\title{
Computerized Auditory Training in Students: Electrophysiological and Subjective Analysis of Therapeutic Effectiveness
}

\author{
Ândrea de Melo ${ }^{1}$ Carolina Lisbôa Mezzomo ${ }^{2}$ Michele Vargas Garcia ${ }^{2}$ Eliara Pinto Vieira Biaggio ${ }^{2}$ \\ ${ }^{1}$ Audiologist, Master Student in Human Communication Disorders, \\ Universidade Federal de Santa Maria, UFSM, Santa Maria, RS, Brazil \\ 2 Department of Speech Pathology/Audiology, Graduate Program in \\ Human Communication Disorders, Universidade Federal de Santa \\ Address for correspondence Ândrea de Melo, Audiologist, Master in \\ Sciences Student, Human Communication Disorders by Universidade \\ Federal de Santa Maria, UFSM, Santa Maria, RS, Brazil \\ (e-mail: andrea.de.melo@hotmail.com).
} Maria, UFSM, Santa Maria, RS, Brazil

Int Arch Otorhinolaryngol 2018;22:23-32.

\begin{abstract}
Keywords

- auditory perception

- electrophysiology

- speech disorders

- acoustic stimulation

- software

Introduction Computerized auditory training (CAT) has been building a good reputation in the stimulation of auditory abilities in cases of auditory processing disorder (APD).

Objective To measure the effects of CAT in students with APD, with typical or atypical phonological acquisition, through electrophysiological and subjective measures, correlating them pre- and post-therapy.

Methods The sample for this study includes 14 children with APD, subdivided into children with APD and typical phonological acquisition (G1), and children with APD and atypical phonological acquisition (G2). Phonological evaluation of children (PEC), long latency auditory evoked potential (LLAEP) and scale of auditory behaviors (SAB) were conducted to help with the composition of the groups and with the therapeutic intervention. The therapeutic intervention was performed using the software Escuta Ativa (CTS Informática, Pato Branco, Brazil) in 12 sessions of 30 minutes, twice a week. For data analysis, the appropriate statistical tests were used.

Results A decrease in the latency of negative wave N2 and the positive wave P3 in the left ear in $\mathrm{G} 1$, and a decrease of $\mathrm{P} 2$ in the right ear in $\mathrm{G} 2$ were observed. In the analysis comparing the pre- and post-CAT groups, there was a significant difference in P1 latency in the left ear and P2 latency in the right ear, pre-intervention. Furthermore, eight children had an absence of the P3 wave, pre-CAT, but after the intervention, all of them presented the $P 3$ wave. There were changes in the SAB score pre- and post-CAT in both groups. The presence of correlation between the scale and some LLAEP components was observed.

Conclusion The CAT produced an electrophysiological modification, which became evident in the effects of the effects of neural plasticity after CAT. The SAB proved to be useful in measuring the therapeutic effects of the intervention. Moreover, there were behavioral changes in the SAB (higher scores) and correlation with LLAEP.
\end{abstract}

received

August 26, 2016 accepted after revision January 2, 2017

published online

April 28, 2017
DOI https://doi.org/

10.1055/s-0037-1600121. ISSN 1809-9777.
Copyright $(2018$ by Thieme Revinter

Publicações Ltda, Rio de Janeiro, Brazil
License terms

(요 (1) $\Theta \circledast$ 


\section{Introduction}

The smallest distinctive units of oral language are the features that make the phonemes of a given language. These are characterized by various sounds that, when combined, allow the development of larger units, such as syllables and words. For the realization of emission, it is necessary that the subject mentally accesses the correct words and phonemes. Therefore, the memory function is essential because it is what allows the storage of such information, aiming to retrieve it later and use it when necessary. ${ }^{1}$ In order for the subject to acquire the perceptual skills, it is fundamental that the central auditory structures are in perfect condition. ${ }^{2}$

The cortical development in humans, which is responsible for the language internalization process through perception, memory and reasoning, ${ }^{3}$ happens during childhood, around the age of 7 .

A possible procedure to evaluate the cortical function related to sonorous events is the long latency auditory evoked potential (LLAEP), which is an electrophysiological measure. This assessment allows the analysis of cortical activities related to discriminating skills, integration and attention in the central nervous system (CNS). ${ }^{4}$ The LLAEP, specifically the $\mathrm{P} 3$ component, has generators in the primary and secondary areas of the auditory cortex, emerging within $300 \mathrm{~ms}$ after the presentation of sonorous stimulations. ${ }^{5}$ Its presence is related to the functional use (assessing the physiological function) of hearing by the subject during the evaluation because it requires conscious attention to the presented stimulus, making it an important component in the research of cognitive and attentional functions. ${ }^{4}$ This component is linked to attention and to recent memory, ${ }^{4}$ both of which are dependent on the auditory discrimination of stimuli (verbal or nonverbal), ${ }^{6}$ making them crucial for the acquisition of the acoustic and phonetic aspects of language, as well as for the learning of written language. ${ }^{7}$ The other waves that compose the LLAEPs, called exogenous potentials $\mathrm{P} 1, \mathrm{~N} 1, \mathrm{P} 2$ and N2, are components that do not require the individual attention of the evaluated subject to present sonorous stimulation, only cortical ability is needed to detect them. ${ }^{8}$

The physiological assessment of the auditory pathway is extremely important for understanding of the auditory processing (AP), and it is used to complement the behavioral assessment. Auditory processing is defined as ability to discriminate, locate or lateralize, recognize, ability to perceive sound in degraded acoustic signals or in acoustic signals in competition, as well as to analyze temporal matters, such as temporal discrimination, integration, ordination and temporal masking. ${ }^{9}$ Any change in one or more processes is diagnosed as auditory processing disorder (APD). This alteration, resulting from a functional neural impairment, gives the subject difficulty in recognizing sound patterns, discriminate different sounds, segment and group sound stimuli, localize sound besides difficulty in ordering speech sounds. ${ }^{10}$ The therapeutic indication in case of APD may be auditory training (AT) for stimulation of lagged skills, ${ }^{11}$ which can be performed with the support of a computer. ${ }^{12}$
This statement is justified due the fact that the AT enables the stimulation of auditory skills through different approaches, according to the individual needs of the subject. This therapeutic procedure aims to reorganize the auditory neural system and its connections with other related sensory systems, helping to establish the auditory skills not mastered by the subject, ${ }^{13}$ as well as promoting plasticity and new cortical organization. ${ }^{14}$

An alternative, attractive and motivating aspect of the AT is the use of software in its therapeutic approach. The computerized auditory training (CAT) enables the therapist to control the stimuli presented, including the establishment of a hierarchy of activities, ${ }^{15}$ as well as the standardization of training. ${ }^{16}$ Data in the literature shows that the use of the software in the therapeutic intervention in children with APD promotes the acquisition of auditory perception skills and other possibilities of learning through the modification of old behaviors. ${ }^{17}$

As previously mentioned, LLAEP is an evaluation procedure that can be sensitive to AP modifications and, its use is attributed as a measure in the monitoring of AT, since there are neurophysiological changes after a therapeutic intervention, in which the patient is his/her own control. ${ }^{18-20}$

In this sense, using additional means of mensuration, such as observation of behavioral auditory changes referred by the subject or by people related to him/her, can be a helpful alternative because they provide a better understanding of the limitations and difficulties caused by APD in the daily life of the patient. A protocol recently translated into Brazilian Portuguese is the Escala de Funcionamento Auditivo ${ }^{21}$ originally named Scale of Auditory Behaviors (SAB) $)^{22}$ protocol, which allows the quantification of the effects of functional hearing impairment caused by changes in auditory abilities in children through questions involving selective attention and focused attention, ability to organize and read, and school performance.

As previously stated, the aim of this study was to measure the effects of CAT in children with APD with typical or atypical phonological acquisition through electrophysiological measures (LLAEP) and subjective measures (SAB). Additionally, it was aimed to verify the use of the $S A B$ as a monitoring tool and its correlation with the components of the electrophysiological evaluation, in the pre- and posttherapeutic intervention periods.

\section{Methodology}

This is a comparative, transversal, longitudinal and experimental study approved by the Ethics Committee of the Universidade Federal de Santa Maria under the number 43171715.0.0000.5346. In addition, this study obeyed the standards and regulatory guidelines for research with human beings of resolution 466/12 of the Brazilian National Health Council. For parents' consent of participation of their children in the research, we used the free and informed consent form (FICF), requiring the signature of the parent/guardian, as well as the participants' consent through the children's consent form.

The inclusion criteria of the study subjects were: presenting auditory thresholds within the standards of normality; ${ }^{23}$ 
introducing changes in speech and/or acquired phonological system; showing APD; not using regular musical instruments; not having performed a previous auditory training; being between seven and eight years old. The exclusion criteria listed were: presenting evident neurological, emotional and/or cognitive commitment; presenting any degree of hearing loss, conductive, mixed or sensorineural type; presenting other oral language changes, such as stuttering, cleft palate and unique phonetic deviation; and the presence of apparent motor or organic changes.

Considering the eligibility criteria listed, the initial case study during the evaluation period had 44 children, 18 of whom were diagnosed with APD after behavioral auditory processing evaluation. It must be emphasized that the children considered as having APD showed changes in at least one hearing ability, according to the indication of the American Speech-Language-Hearing Association. ${ }^{9}$ The reasons recorded for the initial sample loss were: 1) normality of hearing abilities evaluated according to individual performance on a test given to each age group; 2) the adults responsible for three children did not provide consent for their participation in the therapy stage; 3 ) after the beginning of the planning phase of the programmed CAT, there was withdrawal of a subject due to moving to a different city. So, the final sample consisted of 14 children.

As a sample selection method and group composition, an initial battery of assessments was made, composed by the following procedures:

- Anamnesis: Standard anamnesis of the service that covers issues regarding the psychomotor and language development of the children, as well as pregnancy data, presence of a differential diagnosis, history of relatives with hearing loss, school performance, etc.

- Visual inspection of the external auditory canal, pure tone audiometry, speech audiometry and behavioral tests of auditory processing (random gap detection test [RGDT], ${ }^{24}$, pediatric speech intelligibility [PSI] test ${ }^{25}$ and nonverbal dichotic test [NVDT] ${ }^{26}$ ) were conducted in a soundproof booth with a digital two-channel audiometer (Madsen - GN Otometrics, Taastrup, Denmark), Itera model, type II, with TDH series 39 audiometric headphones (Telephonics, Ling Island, NY, USA), with calibration according to the ISO 11957-1986 standard.

- Acoustic immittance measurements and acoustic reflex research performed with a $226 \mathrm{~Hz}$ tone probe and immittanciometer AZ26 (Interacoustic, Middelfart, Denmark), with TDH Series 39 audiometric earphones

- Phonological assessment of child speech (PACS) ${ }^{27}$ to verify the phonological system of the child through spontaneous naming sample in the presence of the five thematic figures of the assessment tool. After that, the contrastive analysis and the calculation of the percentage of consonants correct-revised (PCC-R) ${ }^{28}$ for quantitative deviation classification were used. This analysis was done by two observers separately, who were unaware of each other's evaluation. Both should agree on the transcript, contrastive analysis and calculation of the PCC-R.

After conducting these assessments, the children were distributed into two groups:

G1: Seven children diagnosed with APD and typical phonological system;

G2: Seven children diagnosed with APD and atypical acquisition, independent of the degree of speech.

The assessment procedures and intervention for the two groups were as follows:

- The- SAB, created by Schow and Seikel, ${ }^{22}$ was applied. (-Table 1).

Table 1 Scale of Auditory Behaviors ${ }^{21}$

\begin{tabular}{|c|c|c|c|c|c|}
\hline Behavior items & Frequent & Almost always & Sometimes & Sporadic & Never \\
\hline 1. Difficulty to hear and understand in noisy environment & 1 & 2 & 3 & 4 & 5 \\
\hline $\begin{array}{l}\text { 2. Not understanding when someone speaks quickly } \\
\text { or speak muffled }\end{array}$ & 1 & 2 & 3 & 4 & 5 \\
\hline 3. Difficulty following oral instructions & 1 & 2 & 3 & 4 & 5 \\
\hline $\begin{array}{l}\text { 4. Difficulty in the identification and discrimination of } \\
\text { speaking sounds }\end{array}$ & 1 & 2 & 3 & 4 & 5 \\
\hline 5. Inconsistent responses to auditory information & 1 & 2 & 3 & 4 & 5 \\
\hline 6. Poor reading skills & 1 & 2 & 3 & 4 & 5 \\
\hline 7. Request to repeat things & 1 & 2 & 3 & 4 & 5 \\
\hline 8. Easily distracted & 1 & 2 & 3 & 4 & 5 \\
\hline 9. Academic difficulties or learning & 1 & 2 & 3 & 4 & 5 \\
\hline 10. Short period of attention & 1 & 2 & 3 & 4 & 5 \\
\hline 11. Daydreaming, seems inattentive & 1 & 2 & 3 & 4 & 5 \\
\hline 12. Unorganized & 1 & 2 & 3 & 4 & 5 \\
\hline
\end{tabular}


On this scale,scores lower than 30 points suggest the presence of APD with and indication for intervention and longitudinal follow-up; scores between 30 and 35 points show the need of referral for evaluation of AP, and scores around 46 points indicate normal auditory behavior. ${ }^{21}$

- Electrophysiological evaluation by LLAEP: equipment (Intelligent Hearing Systems, Miami, FL, USA), two channels, with insertion earphones and electrodes positioned on A1 (left mastoid), A2 (right mastoid), Cz (vertex), and the ground $(\mathrm{Fpz})$ on the forehead. It was considered as impedance when the electrodes had values $\leq 3 \mathrm{~K}$-ohms, with a $510 \mathrm{~ms}$ window, alternating polarity, high-pass filter from $30 \mathrm{~Hz}$ and low-pass $1 \mathrm{~Hz}$. The LLAEP-P3 evaluation was performed by presenting the speech stimulus at an intensity of $75 \mathrm{~dB}$ nHL. The frequent stimulus /ba/ and the rare stimulus /di/ were presented in a binaural way. Around 240 frequent stimuli and 60 rare ones (rarefrequent paradigm) were presented. The children were sitting comfortably in an armchair and were instructed to remain relaxed, with eyes open and alert to sound stimuli; they should write down on a sheet each time they heard the rare stimulus and, afterwards, they counted the markings together with the evaluator. We opted for the use of this counting strategy as we believed that it makes it easier for the child to properly register the presence of the rare stimulus. A result was considered suitable when the child hit anywhere from 90 to $95 \%$ of the total of the rare stimuli presented. ${ }^{29}$ The exam would need to be repeated in case of discrepancy between the value of the rare stimuli presented and the total perceived by the child. The evaluation would be repeated at another time; however, there was no need of such care. To avoid the risk of turning the rare stimulus into a frequent one, the tracings were not replicated. Ten percent of the artifacts were accepted. It is important to note that the audio system gets accustomed to hear the frequent sound stimulus, and then a lower number of neurons respond to it; regarding the rare stimulus, there is an activation of more neurons in order to get a response. Therefore, the generated curve is greater than the one formed in response to a frequent stimulus. ${ }^{4} \mathrm{~A}$ potential is generated on the computer at $300 \mathrm{~ms}$ (P300) after each rare stimulus. The latency values were obtained by identification of the waves at the peak of highest amplitude, whereas the cortical auditory evoked potentials P1, N1, P2 and N2 were identified on the tracing of frequent stimuli and cognitive potential, P3, on the tracing of rare stimuli, being the highest positive peak after the exogenous, with latencies between 240 and 400 ms. $^{5}$ The markings were analyzed by three qualified judges (speech therapists) with theoretical knowledge and practical experience in electrophysiological evaluations, especially LLAEP, to confirm the results. Two judges received a copy of the tracings without the proper markings, and each entered the exogenous and endogenous components, and the third judge did the final analysis of such markings. In the present study, only the values of latency were used because this is the measure that, when compared with the amplitude values, suffers less influence from the alteration by neglecting. ${ }^{29}$ Therefore, it is a more reliable measure. $^{30}$

- The therapeutic intervention was performed using the Escuta Ativa ${ }^{31}$ software in 12 sessions, with bi-weekly frequency, and each session lasted $~ 30$ minutes. For the presentation of the sound stimuli, we opted to use supra aural headphones, (Sony, Minato, Tokyo, Japan), MDRZX100 model. The abilities stimulated by this software are: auditory figure-ground skills, integration and binaural separation, temporal resolution, temporal standardization, localization and auditory discrimination. The therapeutic activities were performed in the same order for all children, and only one activity was performed per session, as it can be observed in - Table 2 .

Aiming to monitor the therapeutic evolution and to meet the research objectives, a $\mathrm{SAB}^{21}$ was performed again, two weeks after the end of the CAT, as well as an electrophysiological reassessment.

Statistical measures were applied to verify the obtained values. In the LLAEP evaluation, the Wilcoxon test was applied for intragroup numeric variables; the Mann-Whitney test was used for the analysis of the numerical values between the groups, and, in order to correlate the results of the LLAEP with those of the SAB, we used the Spearman correlation test. In all cases, the significance level adopted was $5 \%(p<0.05)$. For the correlation measures, the following levels were considered: 0 to 0.25 - very weak; 0.25 to 0.50 weak; 0.5 to 0.75 - moderate; 0.75 to 0.9 - strong; and 0.9 to 1 - very strong.

\section{Results}

The difference in the LLAEP findings was analyzed initially, considering the wave latency in both ears, in both groups before and after the CAT, as shown in - Table 3.

One can observe a statistically significant difference post-CAT, regarding the decrease of latency in the N2 wave in the left ear and in the P3 in the left ear in G1, as well as the decrease of latency in the P2 wave in the right ear in G2.

It is important to highlight that when analyzing only the presence of the P3 component, pre-CAT, in a descriptive way, in G1, three children presented this component bilaterally, and one in the left ear, and G2 showed the same results. After the CAT, all children, regardless of the group, presented P3.

In addition to that, in the comparison of the latency values between the groups, we observed a pre-CAT difference related to the P1 wave in the left ear, and to the P2 wave in the right ear, as in - Table 4.

As for the performance observed by the parents, regarding the behavioral change in children, after intervention by operating hearing $S A B$, a significant value was obtained in the comparison between the groups pre- $(p=0.041)$ and post- ( $p=0.025$ ) CAT. Additionally, there was a significant 
Table 2 Presentation of the twelve activities that compose the Escuta Ativa software and brief explanation of them

\begin{tabular}{|l|l|}
\hline Activity & Explanation \\
\hline How many intervals & Pure tones, songs and phrases. The subject should identify the intervals between stimuli. \\
\hline Follow the flute & Two words were presented and it should be answered if they are different or the same. \\
\hline Follow the piano & $\begin{array}{l}3 \text { to } 5 \text { sounds that differ in duration were presented by a flute, and the sound heard } \\
\text { should be repeated. }\end{array}$ \\
\hline Follow the sequence & $\begin{array}{l}3 \text { to } 5 \text { sounds that differ in frequency were presented by a piano, and the sound heard } \\
\text { should be repeated. }\end{array}$ \\
\hline Target shooting & $\begin{array}{l}\text { A sequence of sounds was presented and the subject should reproduce the sequence } \\
\text { heard by clicking on the image of the corresponding sounds. For this activity children } \\
\text { had the help of a picture containing the alphabet, in those activities that requested } \\
\text { organization of the heard sounds as alphabetical order or reverse order }\end{array}$ \\
\hline Left-right & $\begin{array}{l}\text { The sound (numbers, words or sentences) was presented in a dichotic way, and it should } \\
\text { be identified from which side the sound came }\end{array}$ \\
\hline Binaural & $\begin{array}{l}\text { Dichotic words were presented, and it should be identified which word came from either } \\
\text { side by selecting the corresponding word in the picture }\end{array}$ \\
\hline How many sounds & $\begin{array}{l}\text { It was expected that the child could identify the location and distance of the sound, by } \\
\text { presenting different sounds and simulating different locations }\end{array}$ \\
\hline Listening and attention & Various sounds were presented, and the amount of sounds heard was requested \\
\hline Bonus: Catch if you can & Two words were heard and it should be verified if they were agreeing with the statement \\
\hline Bonus: Follow the rhythm & $\begin{array}{l}\text { The children should observe the movement of the pictures and click on them. } \\
\text { notes according to the song heard. }\end{array}$ \\
\hline
\end{tabular}

result in the intra-group performance, as observed in -Fig. 1.

A statistical difference is observed in both groups in the $\mathrm{SAB}$ scores pre- and post-CAT, with an increase in values. In -Table 5, it is possible to see the correlation between the latency values of LLAEP waves and the score in the SAB intragroup.

As for the performance in the SAB and the measures of positive waves $\mathrm{P} 1, \mathrm{P} 2$ and $\mathrm{P} 3$ and negative waves $\mathrm{N} 1$ and $\mathrm{N} 2$, it was possible to observe a positive correlation only in G2. Regarding the latency, there was a moderate correlation in the N1 wave in the left ear, and a strong correlation in the $\mathrm{N} 1$ wave in the right ear pre-CAT, as well as a moderate correlation in the $\mathrm{N} 2$ wave in the left ear postCAT in G2.

In - Table 6, one can observe the correlation between the $\mathrm{SAB}$ and the LLAEP component, in milliseconds, with no distinction of groups, in the analysis pre- and post-CAT.

There was a moderate positive correlation on the N1 wave latency in the left ear pre-CAT.

\section{Discussion}

It is noteworthy that, in this study, the criterion of normal or altered was not used because there is disagreement in the literature regarding the normalization values for each age group. ${ }^{6}$ Therefore, the numeric values of the LLAEP were considered for the purpose of analysis.

As for the latency values for the LLAEP components, there was a statistically significant difference in the analysis of the $\mathrm{N} 2$ and $\mathrm{P} 3$ components in the left ear, pre- and post-CAT, in
G1 (-Table 3). In G2, there was a statistical difference for the P2 wave in the right ear pre- and post-CAT. It was inferred that this difference indicates evidence of neurofunctional changes in the auditory processing post-therapeutic intervention. In the analysis of the endogenous component, P3, the average values of this component latency were higher in G2, both pre- and post-CAT; however, there was no statistically significant difference.

Data in the literature shows the following latency values for LLAEP waves in the population with phonological disorder (PD), regardless of the ear: N1 $-113.5 \mathrm{~ms}$; P2 159.5ms; N2 - 233.2ms; and P3 - 353.2ms. ${ }^{32}$ They also state that the latency of $\mathrm{P} 3$ appeared to be increased in the group with PD when compared with children with typical phonological acquisition. In the present study, increased latency values for some exogenous components were observed in both groups (-Tables 3 and $\mathbf{4}$ ); however, because it is an assessment performed in children, such results were regarded as part of the maturation process of the central auditory pathway.

The N2 wave is not only an exogenous component, as it is believed that it depends on the processing of sonorous stimuli, ${ }^{33}$ as well as on cognitive processes such as attention and perception.,34 The same could be said about higher levels of the cortex with the function of controlling the attention ability. ${ }^{35}$ Therefore, it can be inferred that there was an improvement in the attentional factor of children in G1 by the statistical difference observed in both the N2 and P3 components.

There is a shortage of studies made with LLAEPs and subjects with atypical phonological acquisition. However, 
Table 3 Comparison between latencies, in milliseconds, of LLAEP pre- and post-therapeutic intervention in children with APD and typical or atypical speech acquisition

\begin{tabular}{|c|c|c|c|c|c|c|c|c|c|}
\hline & \multicolumn{4}{|l|}{ PRE-CAT } & \multicolumn{4}{|c|}{ POST-CAT } & \multirow[t]{2}{*}{$p^{*}$} \\
\hline & Average & SD & Min. & Max. & Average & SD & Min. & Max. & \\
\hline \multicolumn{10}{|c|}{$\mathrm{G} 1(n=7)$} \\
\hline P1 RE & 71.40 & 11.44 & 58 & 82 & 71.80 & 8.98 & 61 & 83 & 0.500 \\
\hline P1 LE & 69.20 & 6.94 & 61 & 79 & 80.60 & 10.88 & 69 & 97 & 0.079 \\
\hline N1 RE & 134.40 & 17.50 & 117 & 156 & 143.00 & 25.37 & 117 & 183 & 0.500 \\
\hline N1 LE & 129.40 & 15.92 & 113 & 147 & 131.80 & 19.25 & 108 & 155 & 0.418 \\
\hline P2 RE & 187.83 & 40.27 & 158 & 267 & 196.41 & 33.89 & 158 & 254 & 0.463 \\
\hline P2 LE & 196.67 & 36.78 & 162 & 256 & 188.71 & 43.09 & 141 & 265 & 0.248 \\
\hline N2 RE & 270.67 & 38.09 & 230 & 316 & 275.85 & 33.29 & 240 & 319 & 0.916 \\
\hline N2 LE & 267.43 & 32.85 & 224 & 306 & 258.43 & 43.44 & 180 & 305 & $0.018^{* *}$ \\
\hline P3 RE & 366.00 & 12.25 & 357 & 384 & 364.71 & 36.37 & 335 & 442 & 0.144 \\
\hline P3 LE & 369.80 & 14.41 & 357 & 394 & 360.14 & 35.93 & 334 & 437 & $0.043^{* *}$ \\
\hline \multicolumn{10}{|c|}{$\mathrm{G} 2(n=7)$} \\
\hline P1 RE & 82.50 & 9.81 & 67 & 97 & 78.29 & 10.53 & 56 & 87 & 0.500 \\
\hline P1 LE & 81.67 & 9.40 & 68 & 95 & 75.57 & 13.81 & 56 & 95 & 0.500 \\
\hline N1 RE & 153.57 & 48.90 & 118 & 256 & 134.86 & 28.12 & 111 & 182 & 0.310 \\
\hline N1 LE & 153.29 & 49.61 & 114 & 259 & 139.57 & 31.85 & 113 & 200 & 0.447 \\
\hline P2 RE & 229.14 & 61.94 & 180 & 363 & 198.00 & 26.47 & 172 & 248 & $0.028^{* *}$ \\
\hline P2 LE & 223.29 & 62.20 & 170 & 367 & 194.71 & 25.64 & 166 & 243 & 0.063 \\
\hline N2 RE & 269.80 & 14.67 & 256 & 287 & 270.00 & 21.85 & 227 & 294 & 0.893 \\
\hline N2 LE & 270.40 & 17.97 & 250 & 288 & 267.29 & 21.91 & 229 & 314 & 0.418 \\
\hline P3 RE & 397.75 & 38.22 & 367 & 453 & 376.85 & 24.11 & 357 & 425 & 0.144 \\
\hline P3 LE & 389.00 & 32.65 & 370 & 447 & 372.17 & 25.90 & 334 & 410 & 0.224 \\
\hline
\end{tabular}

Abbreviations: APD, auditory processing disorder; CAT, computerized auditory training; $\mathrm{G1}$, auditory processing disorder and typical phonological acquisition group; G2, auditory processing disorder and atypical phonological acquisition group; LE, left ear; LLAEP, long latency auditory evoked potential; Max., maximum; Min., minimum; n, number of subjects; RE, right ear; SD, standard deviation.

Notes: * Statistically significant difference.

** Concerning the Wilcoxon test for comparison of numerical variables in groups, the significance level was of $5 \%(p<0.05)$.

one can find researches conducted with children presenting learning complaints, in which P3 wave values are similar to the ones in the present research. This fact confirms the diagnostic of APD already identified by means of behavioral tests and LLAEP, with average values for P3 in the right ear of $350.33 \mathrm{~ms}$, and in the left ear of $330.08 \mathrm{~ms}^{36}$ In another survey, held with 21 children aged 7 to 14 years old, diagnosed with reading and writing problems, a latency average value of $334.25 \mathrm{~ms}$ for the $\mathrm{P} 3$ wave was obtained. ${ }^{37}$ The increased value of P3 latency in children with learning problems is related to the child's need for more time to perceive the sound stimulus, being proportional to the claim that the longer the time to notice the sounds, the greater will be the P3 wave latency. ${ }^{38}$ Higher latency values found in this study in G2 lead us to think that children with APD associated to atypical phonological acquisition show more difficulty in quickly noticing the change of sounds at a cortical level, a fact that should be considered in the therapeutic approach and speech therapy of these children.
There was a decrease in latency of the P3 wave comparison of pre and post-CAT in both groups. However, this difference was statistically significant only for G1 left ear, to intragroup comparison and there was no significant difference in the comparison between groups.

However, it should be noted that eight children had no P3 wave pre-CAT, six bilaterally and two unilateral (right ear), with no difference between groups and, after intervention, all children presented P3 wave, reinforcing the effects of plasticity before the stimulation. The findings of this study show that there were changes in wave latency, even in the absence of statistical difference in most of them, since in the individual analysis of the tests, all the children obtained a decrease in latency, or, in those whose values were increased, justifying by the emergence of the post-CAT wave.

The important change observed in the left ear regarding the P3 wave, particularly in G1, shows greater activation of the callous corpus participation, which is responsible for the 
Table 4 Comparison between latencies, in milliseconds, in the LLAEP pre and post-therapeutic intervention in children with APD and typical or atypical speech acquisition, considering the variable group

\begin{tabular}{|c|c|c|c|c|c|c|c|c|c|}
\hline & \multicolumn{4}{|c|}{$\mathrm{G} 1(n=7)$} & \multicolumn{4}{|c|}{$\mathrm{G} 2(n=7)$} & \multirow[t]{2}{*}{$p^{*}$} \\
\hline & Average & SD & Min. & Max. & Average & SD & Min. & Max. & \\
\hline \multicolumn{10}{|c|}{ PRE-CAT } \\
\hline P1 RE & 71.40 & 11.44 & 58 & 82 & 82.50 & 9.81 & 67 & 97 & 0.082 \\
\hline P1 LE & 69.20 & 6.94 & 61 & 79 & 81.67 & 9.40 & 68 & 95 & $0.035^{* *}$ \\
\hline N1 RE & 134.40 & 17.50 & 117 & 156 & 153.57 & 48.90 & 118 & 256 & 0.535 \\
\hline N1 LE & 129.40 & 15.92 & 113 & 147 & 153.29 & 49.61 & 114 & 259 & 0.372 \\
\hline P2 RE & 187.83 & 40.27 & 158 & 267 & 229.14 & 61.94 & 180 & 363 & $0.045^{* *}$ \\
\hline P2 LE & 196.67 & 36.78 & 162 & 256 & 223.29 & 62.20 & 170 & 367 & 0.391 \\
\hline N2 RE & 270.67 & 38.09 & 230 & 316 & 269.80 & 14.67 & 256 & 287 & 1.000 \\
\hline N2 LE & 267.43 & 32.85 & 224 & 306 & 270.40 & 17.97 & 250 & 288 & 0.807 \\
\hline P3 RE & 366.00 & 12.25 & 357 & 384 & 397.75 & 38.22 & 367 & 453 & 0.083 \\
\hline P3 LE & 369.80 & 14.41 & 357 & 394 & 389.00 & 32.65 & 370 & 447 & 0.117 \\
\hline \multicolumn{10}{|c|}{ POST-CAT } \\
\hline P1 RE & 71.80 & 8.98 & 61 & 83 & 78.29 & 10.53 & 56 & 87 & 0.223 \\
\hline P1 LE & 80.60 & 10.88 & 69 & 97 & 75.57 & 13.81 & 56 & 95 & 0.569 \\
\hline N1 RE & 143.00 & 25.37 & 117 & 183 & 134.86 & 28.12 & 111 & 182 & 0.416 \\
\hline N1 LE & 131.80 & 19.25 & 108 & 155 & 139.57 & 31.85 & 113 & 200 & 0.808 \\
\hline P2 RE & 196.43 & 33.38 & 158 & 254 & 198.00 & 26.47 & 172 & 248 & 0.898 \\
\hline P2 LE & 188.71 & 43.09 & 141 & 265 & 194.71 & 25.64 & 166 & 243 & 0.565 \\
\hline N2 RE & 275.85 & 33.29 & 240 & 319 & 270.00 & 21.85 & 227 & 294 & 0.949 \\
\hline N2 LE & 258.43 & 43.44 & 180 & 305 & 267.29 & 21.91 & 229 & 314 & 0.655 \\
\hline P3 RE & 364.71 & 36.37 & 335 & 442 & 376.85 & 24.11 & 357 & 425 & 0.180 \\
\hline P3 LE & 360.14 & 35.93 & 334 & 437 & 372.17 & 25.90 & 334 & 410 & 0.284 \\
\hline
\end{tabular}

Abbreviations: APD, auditory processing disorder; CAT, computerized auditory training; G1, auditory processing disorder and typical phonological acquisition group; G2, auditory processing disorder and atypical phonological acquisition group; LE, left ear; LLAEP, long latency auditory evoked potential; Max., maximum; Min., minimum; n, number of subjects; RE, right ear; SD, standard deviation.

Notes: * Statistically significant difference.

${ }^{* *}$ Concerning the Mann-Whitney test for comparison of numerical variables between groups, the significance level was of $5 \%(p<0.05)$.

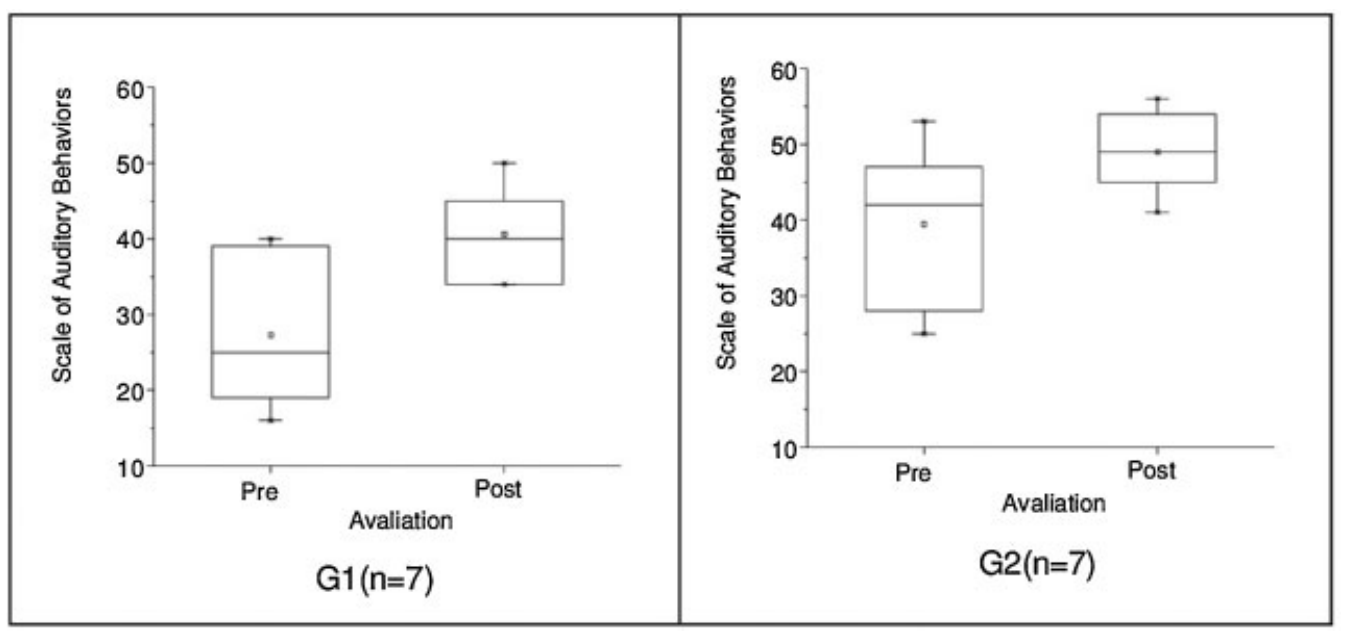

Fig. 1 Analysis performance on intragroup scale of auditory behaviors, as the behavioral changes reported by patients or guardians of children in the study.

Abbreviations: G1, auditory processing disorder and typical phonological acquisition group; G2, auditory processing disorder and atypical phonological acquisition group; $\mathrm{n}$, number of subjects. 
30 Electrophysiological and Subjective Analysis of Therapeutic Effectiveness Melo et al.

Table 5 Correlation analysis of the SAB and the performance in the electrophysiological evaluations, latency measured in milliseconds, pre- and post-therapeutic intervention in children with APD and typical or atypical speech acquisition

\begin{tabular}{|c|c|c|c|c|c|c|c|c|}
\hline & \multicolumn{4}{|l|}{ G1 $(n=7)$} & \multicolumn{4}{|l|}{$G 2(n=7)$} \\
\hline & \multicolumn{2}{|l|}{ PRE-CAT } & \multicolumn{2}{|l|}{ POST-CAT } & \multicolumn{2}{|l|}{ PRE-CAT } & \multicolumn{2}{|l|}{ POST-CAT } \\
\hline & $\begin{array}{l}r \\
\text { (Spearman) }\end{array}$ & $p$ & $\begin{array}{l}r \\
\text { (Spearman) }\end{array}$ & $p$ & $\begin{array}{l}r \\
\text { (Spearman) }\end{array}$ & $p$ & $\begin{array}{l}r \\
\text { (Spearman) }\end{array}$ & $p$ \\
\hline P1 RE & 0.20000 & 0.7471 & 0.15789 & 0.7998 & -0.31887 & 0.5379 & -0.16366 & 0.7259 \\
\hline P1 LE & 0.20000 & 0.7471 & 0.20520 & 0.7406 & 0.00000 & 1.0000 & -0.07143 & 0.8790 \\
\hline N1 RE & 0.00000 & 1.0000 & 0.56429 & 0.3217 & $0.90094^{*}$ & 0.0056 & 0.42857 & 0.3374 \\
\hline N1 LE & 0.40000 & 0.5046 & -0.20520 & 0.7406 & $0.85714^{*}$ & 0.0137 & 0.57143 & 0.1802 \\
\hline P2 RE & -0.14284 & 0.7872 & -0.34236 & 0.4523 & 0.67857 & 0.0938 & 0.39286 & 0.3833 \\
\hline P2 LE & -0.34786 & 0.4993 & -0.48651 & 0.2682 & 0.67857 & 0.0938 & 0.46429 & 0.2939 \\
\hline N2 RE & -0.42857 & 0.3965 & -0.45047 & 0.3104 & -0.20000 & 0.7471 & 0.32143 & 0.4821 \\
\hline N2 LE & -0.63066 & 0.1289 & -0.54056 & 0.2103 & 0.20000 & 0.7471 & $0.78571^{*}$ & 0.0362 \\
\hline P3 RE & 0.60000 & 0.4000 & 0.48651 & 0.2682 & 0.00000 & 1.0000 & -0.57143 & 0.1802 \\
\hline P3 LE & -0.04000 & 0.5046 & 0.39641 & 0.3786 & 0.60000 & 0.2848 & -0.37143 & 0.4685 \\
\hline
\end{tabular}

Abbreviations: APD, auditory processing disorder; CAT, computerized auditory training; G1, auditory processing disorder and typical phonological acquisition group; $G 2$, auditory processing disorder and atypical phonological acquisition group; LE, left ear; $n$, number of subjects; $r$, Spearman correlation; RE, right ear; SAB, scale of auditory behaviors.

Note: ${ }^{*}$ Significant correlation value considering $r=0$ to 0.25 : very weak; 0.25 to 0.50 : weak; 0.5 to 0.75 : moderate; 0.75 to 0.9 : strong; and 0.9 to 1 : very strong.

connection between the hemispheres, therefore making the processing of the auditory verbal stimuli efficient. ${ }^{39}$ This result, regarding the decrease in P3 latency, was confirmed in a previous study in a child with APD after four months of formal and informal associated therapy, ${ }^{40}$ and also in AT in a soundproof booth in 29 children with APD. ${ }^{18}$ Authors conducting research with adults defend that the reduced latency of the P3 wave is related to the increase in cognitive ability, and that this evaluation can bring information about behavioral changes with late development. ${ }^{41}$

In comparison with the other waves regarding the latency values between the groups, higher values in G2 were obtained pre-Cat for the latencies of the P1 wave in the left ear and the P2 wave in the right ear (-Table 4). These findings

Table 6 Correlation analysis of the SAB and the performance in the electrophysiological evaluation, considering values of latency in milliseconds, pre- and post-therapeutic intervention, the entire sample $(n=14)$

\begin{tabular}{|c|c|c|c|c|}
\hline & \multicolumn{2}{|l|}{ PRE-CAT } & \multicolumn{2}{|l|}{ POST-CAT } \\
\hline & $\begin{array}{l}r \\
\text { (Spearman) }\end{array}$ & $p$ & $\begin{array}{l}\mathrm{r} \\
\text { (Spearman) }\end{array}$ & $p$ \\
\hline \multicolumn{5}{|c|}{ Latency } \\
\hline P1 RE & 0.30206 & 0.3666 & 0.13855 & 0.6676 \\
\hline P1 LE & 0.58353 & 0.0595 & -0.07055 & 0.8275 \\
\hline N1 RE & 0.56591 & 0.0551 & 0.27817 & 0.3813 \\
\hline N1 LE & $0.66550^{*}$ & 0.0182 & 0.35501 & 0.2575 \\
\hline P2 RE & 0.48693 & 0.0915 & 0.05740 & 0.8455 \\
\hline P2 LE & 0.29890 & 0.3212 & 0.08820 & 0.7643 \\
\hline N2 RE & -0.23235 & 0.4918 & -0.14995 & 0.6089 \\
\hline N2 LE & -0.31228 & 0.3231 & 0.06174 & 0.8339 \\
\hline P3 RE & 0.52381 & 0.1827 & 0.22051 & 0.4487 \\
\hline P3 LE & 0.41818 & 0.2291 & 0.11740 & 0.7025 \\
\hline
\end{tabular}

Abbreviations: APD, auditory processing disorder; CAT, computerized auditory training; LE, left ear; $n$, number of subjects; r, Spearman correlation; $\mathrm{RE}$, right ear; $\mathrm{SAB}$, scale of auditory behaviors.

${ }^{*}$ significant correlation value considering $r=0$ to 0.25 : very weak, 0.25 to 0.50 : weak, 0.5 to 0.75 : moderate, 0.75 to 0.9 : strong and, 0.9 to 1 : very strong. 
relate to a recent research conducted with two groups (children with normal learning and children with learning problems), in which a difference was detected in the averages of the N1, P2 and N2 waves latencies in the left ear, and N1 and $\mathrm{P} 2$ waves in the right ear, with increased values in the group diagnosed with learning disorder. ${ }^{42}$ Speech changes, as well as learning ${ }^{34,35}$ in children, show an increase in the values of cortical auditory evoked potentials in the electrophysiological evaluation.

Both electrophysiological and functional behavioral changes in the AP of children pre- and post-therapeutic intervention were observed, confirming that the CAT proved to be an effective procedure in the group studied ( - Table 4 and - Fig. 1). This result is in accordance with the concepts of neuropsychology, which argue that in order to modify cognitive functions in the rehabilitation process two variables must be present: neural plasticity and functional plasticity. The first relates to the CNS's ability to recover an activity through neural proliferation, migration and synaptic interactions. The second is characterized by the recovery degree of a function using modified behavioral approaches. ${ }^{43}$

We detected a moderate negative correlation in the latency of the $\mathrm{P} 3$ wave in the right ear in $\mathrm{G} 2$ and the postCAT SAB. This is an interesting fact because the higher the score, the lower the value of the latency of P3 wave should be. In other words, closer than the expected. This finding shows that this improvement was perceived not only biologically through the electrophysiological test, but also on behavioral changes observed by the children's parents. However, we could not find, in the consulted literature, studies seeking the correlation between the AP electrophysiological evaluation and the SAB (as performed and exposed in - Table 5). Yet, there are studies showing correlation between the AP behavioral tests and the SAB in children, in which there was a positive correlation, especially in tests involving temporal abilities. ${ }^{21,44,45}$ It is known that the higher the score on the scale, the better the performance on behavioral tests. ${ }^{21,44}$ Data in the literature also state that, if children present a lower score on the SAB and normal results in the AP tests, they should be followed-up for a period of at least one year. ${ }^{46}$

In the correlation between the SAB and the LLAEP, without distinction of groups, the wave's correlation was lower, present only for the latency of N1 in the left ear, pre-CAT (- Table 6). It is known that $\mathrm{N} 1$ is associated with the ability of attention and the initial decoding process, and its generator site is the supratemporal auditory cortex, the first site of the auditory pathway in the LLAEP $^{37}$ record. Regarding the significant difference to left ear, it was not possible to infer this finding.

According to the presented results, this study showed that the CAT in the studied population provided changes in the central auditory pathway level and related systems with decrease in the wave's latency, even in the absence of a statistically significant difference, reinforcing the CNS's ability to shape up towards acoustic stimulation due to neural plasticity. Although the data of the present study already indicate electrophysiological changes after CAT, we emphasize the importance of more studies with a larger sample, since the sample size was a limitation in this case. Therefore, we can infer that the use of software as a means of therapeutic intervention generated positive changes, both in the group with APD alone and in those who presented associated atypical phonological acquisition. Positive changes were also confirmed by the SAB, regarding the functional behavior of hearing.

\section{Conclusion}

In this study, the CAT program searched for changes occurred in electrophysiological responses. There were significant differences, such as the reduction of the N2 and P3 latencies in the left ear in G1, and the decreased P2 latency in the right ear in G2. In the analysis of the comparison between the groups, before and after CT, there was a significant difference in P1 latency in the left ear and P2 latency in the right ear before the intervention. In addition, eight children presented absence of wave $\mathrm{P} 3$ pre-CAT and, after intervention, all presented $\mathrm{P} 3$ wave.

Substantial behavioral changes were also noted in the SAB score (score increase), which proved to be an effective tool in the measurement of therapeutic efficacy. There was a correlation between the LLAEP electrophysiological evaluation and the SAB, especially in N1 and N2 in G2.

\section{References}

1 Tabaquim MLM. Exame neuropsicológico e análise de funções corticais superiores. Mimesis, Bauru. 2010;32:115-140

2 Alvarenga KdeF, Vicente LC, Lopes RCF, et al. The influence of speech stimuli contrast in cortical auditory evoked potentials. Rev Bras Otorrinolaringol (Engl Ed) 2013;79(03):336-341

3 Damasceno BP. Development of superior cortical functions. Moura-Ribeiro MVL, Gonçalves VMG. Child Neurology Development. Rio de Janeiro: Revinter; 2010

4 McPherson DL. Long Latency auditory evoked potentials. . In: Late Potentials of The auditory system. Singular Publishing Group, Inc; 1996:7-21

5 Junqueira CAO, Colafêmina JF. Investigation of inter- and intraexaminer stability to P300 auditory identification: analysis of errors. Rev Bras Otorrinolaringol 2002;68:468-478

6 Mendonça EBS, Muniz LF, Leal MdeC, Diniz AdaS. Applicability of the $\mathrm{P} 300$ frequency pattern test to assess auditory processing. Rev Bras Otorrinolaringol (Engl Ed) 2013;79(04):512-521

7 Lemos ICC, Feniman MR. Sustained Auditory Attention Ability Test (SAAAT) in seven-year-old children with cleft lip and palate. Rev Bras Otorrinolaringol (Engl Ed) 2010;76(02):199-205

8 Sleifer P. Avaliação eletrofisiológica da audição em crianças. . In: Cardoso MC (Org.). Fonoaudiologia na infância: avaliação e tratamento. Rio de Janeiro: Revinter; 2014:171-94

9 American Speech-Language Hearing Association2005Central) Auditory Processing Disorders- Working Group on Auditory Processing Disorders [Technical Report]. . Available at: http:// www.asha.org/policy/TR2005-00043/\#d4e877

10 British Society of AudiologyAn overview of current management of auditory processing disorder (APD). London: BSA; 2011. Accessed Setember 07, 2015. Available at: http://www.thebsa.org. uk/resources/overview-current-management-auditory-processing-disorder-apd/

11 Vilela N, Wertzner HF, Sanches SGG, Neves-Lobo IF, Carvallo RM. Temporal processing in children with phonological disorders submitted to auditory training: a pilot study. J Soc Bras Fonoaudiol 2012;24(01):42-48 
12 Thibodeau LM. Computer-based auditory training (CBAT) for (Central) auditory processing disorders. Chermak GD, Musiek FE. Handbook of (central) auditory processing disorder: comprehensive intervention. San Diego: Plural Publishing; 2007: 167-206

13 Musiek F, Shinn J, Hare C. Plasticity, auditory training, and auditory processing disorders. Semin Hear 2002;23:263-276

14 Cruz ACA, Andrade AN, Gil D. Effectiveness of formal auditory training in adults with auditory processing disorder. Rev CEFAC. 2013;15:1427-1434

15 Comerlatto AA Junior, Silva MP, Balen AS. A software for auditory rehabilitation of central auditory processing disorder children. Rev Neurocienc. 2010;18:454-462

16 Balen SA, Silva LTN. Programas computadorizados no treinamento auditivo. Bevilacqua MC, Menezes PL, Couto CM, Frizzo ACF, Scharlach RC, Anastásio ART. et al. Tratado de Audiologia. São Paulo: Santos; 2011:805-28

17 Martins JS, Pinheiro MMC, Blasi HF. A utilização de um software infantil na terapia fonoaudiológica de Distúrbio do Processamento Auditivo Central. Rev Soc Bras Fonoaudiol 2008; 13:398-404

18 Alonso R, Schochat E. The efficacy of formal auditory training in children with (central) auditory processing disorder: behavioral and electrophysiological evaluation. Rev Bras Otorrinolaringol (Engl Ed) 2009;75(05):726-732

19 George EM, Coch D. Music training and working memory: an ERP study. Neuropsychologia 2011;49(05):1083-1094

20 Francelino EG, Reis CFC, Melo T. The use of P300 with speech stimulus for monitoring the auditory training. Distúrb Comu. 2014;26:27-34

21 Nunes CL, Pereira LD, Carvalho GS. Scale of Auditory Behaviors and auditory behavior tests for auditory processing assessment in Portuguese children. CoDAS 2013;25(03):209-215

22 Schow RL, Seikel JA. Screening for (central) auditory processing disorder. Chermak G, Musiek F. Handbook of (central) Auditory Processing Disorder: Auditory neuroscience and diagnosis. San Diego, CA: Plural Pub; 2006:137-61

23 Northern JL, Downs MP. Audição na infância. 5ª edição. Rio de Janeiro: Guanabara Koogan; 2005

24 Keith RWRGDT - Random gap detection test. Auditec of St. Louis2000

25 Ziliotto KN, Kalil DM, Almeida CIR. PSI em português. Pereira LD, Schochat E. Processamento auditivo central: manual de avaliação. São Paulo: Lovise; 1997:113-28

26 Ortiz KZ, Pereira LD. Não-verbal de escuta direcionada. Pereira LD, Schochat E. Processamento auditivo central: manual de avaliação. São Paulo: Lovise; 1997:151-8

27 Yavas M, Hernandorena CL, Lamprecht RR. Avaliação fonológica da criança: reeducação e terapia. Porto Alegre: Artes Médicas; 1991

28 Shriberg LD, Austin D, Lewis BA, McSweeny JL, Wilson DL. The percentage of consonants correct (PCC) metric: extensions and reliability data. J Speech Lang Hear Res 1997;40(04):708-722

29 Kraus N, McGee T. Potenciais evocados auditivos de longa latência. Katz J. Tratado de audiologia clínica. 4.ed.. São Paulo: Manole; 2002:403-20
30 Picton TW. The P300 wave of the human event-related potential. J Clin Neurophysiol 1992;9(04):456-479

31 Alvarez A, Sanchez ML, Guedes MC. Escuta Ativa - Avaliação e Treinamento Auditivo Neurocognitivo. CTS InformáticaPato Branco, PR2010

32 Leite RA, Wertzner HF, Matas CG. Long latency auditory evoked potentials in children with phonological disorder. Pro Fono 2010; 22(04):561-566

33 Sams M, Alho K, Näätänen R. Sequential effects on the ERP in discriminating two stimuli. Biol Psychol 1983;17(01):41-58

34 Barry RJ, Johnstone SJ, Clarke AR. A review of electrophysiology in attention-deficit/hyperactivity disorder: II. Event-related potentials. Clin Neurophysiol 2003;114(02):184-198

35 Johnstone SJ, Barry RJ, Anderson JW, Coyle SF. Age-related changes in child and adolescent event-related potential component morphology, amplitude and latency to standard and target stimuli in an auditory oddball task. Int J Psychophysiol 1996; 24(03):223-238

36 Soares AJC, Sanches SGG, Neves-Lobo IF, Carvallo RMM, Matas CG Cárnio MS. Long latency auditory evoked potentials and central auditory processing in children with reading and writing alterations: preliminary data. Arq Int Otorrinolaringol 2011;15:486-491

37 Wiemes GRM, Kozlowski L, Mocellin M, Hamerschmidt R, Schuch LH. Cognitive evoked potentials and central auditory processing in children with reading and writing disorders. Rev Bras Otorrinolaringol (Engl Ed) 2012;78(03):91-97

38 Purdy SC, Kelly AS, Davies MG. Auditory brainstem response, middle latency response, and late cortical evoked potentials in children with learning disabilities. J Am Acad Audiol 2002;13(07): 367-382

39 Musiek FE, Weihing J. Perspectives on dichotic listening and the corpus callosum. Brain Cogn 2011;76(02):225-232

40 Kozlowski L, Wiemes GMR, Magni C, Silva ALG. The effectiveness of the auditory training in the central auditory processing disorder: a case study. Rev Bras Otorrinolaringol 2004;70:427-432

41 Matas CG, Hataiama NM, Gonçalves IC. Stability of auditory evoked potentials in adults with normal hearing. Rev Soc Bras Fonoaudiol 2011;16:37-41

42 Regaçone SF, Gução ACB, Giacheti CM, Romero ACL, Frizzo ACF. Long latency auditory evoked potentials in students with specific learning disorders. Audiol Commun Res. 2014;19:13-18

43 McCoy KD, Gelder BC, VanHorn RE, Dean RS. Approaches to the Cognitive Rehabilitation of Children with Neuropsychological Impairment. Feinberg TE, Farah MJ. Behavioural Neurology and NeuropsychologyMcGraw-Hill1997

44 Silva IMC, Nogueira AG, Lagares AD, Lima ELF, Sant'Anna T. Comparação do escore no questionário SAB com a avaliação formal do processamento auditivo. $29^{\circ}$ Encontro Internacional de Audiologia (EIA)Florianópolis2014:819

45 Nunes CL. A avaliação do processamento auditivo em crianças de 10 a 13 anos: sua função como indicador da perturbação da comunicação e do desempenho académico [thesis]. Braga: Universidade do Minho; 2012

46 Summers SA. Factor structure, correlations, and mean data on Form A of the Beta III version of Multiple Auditory Processing Assessment (MAPA). Idaho State UniversityPocatello, ID2003 